\title{
Household food security and associated factors among Adult people living with HIV/AIDS attending ART clinic in Hospitals of Hawassa Town, Southern Ethiopia 2017
}

REKIKU Fikre ABEBE ( $\square$ frekiku@yahoo.com )

Hawassa University College of Medicine and Health Sciences

Tamrayhu seyoum

south region health bureau

Research article

Keywords: Food security, disclosures, Household size

Posted Date: April 29th, 2019

DOI: https://doi.org/10.21203/rs.2.9380/v1

License: @ (i) This work is licensed under a Creative Commons Attribution 4.0 International License. Read Full License 


\section{Abstract}

Abstract Introduction: Globally 78 million peoples have been infected with HIV/AIDS. Ethiopia has one of the largest populations of HIV infected people in the sub-Saharan region of Africa. The relationship between HIV epidemic and food security situation in Ethiopia is complex. Hence, it is likely that the epidemic will contribute to worsening widespread food insecurity. The aim of study was to assess the level of food security and associated factors among adult people living with HIV / AIDS attending ART Clinic in Hospitals of Hawassa city Administration. Methodology: Thisinstitutional based cross-sectional study was conducted from October to December 2017. Systematic sampling technique was used to select a total of 532 study participant. Data entry was done with EPI-info version 3.5.3 and transferred into SPSS Version 20. Crude with adjusted odds ratio with $95 \%$ confidence interval at $p$-value $<0.05$ were computed to examine statistical significance. Results:Based on food security assessment core module scale 360 (67.3\%) People living with HIV/AIDSwere food insecure. People living with HIV/AIDSwho disclose HIV status were 3.9 (AOR=3.902, 95\% Cl (1.238, 12.301) times more likely to be food secured compared with their counterparts.Similarly, those who were with high and medium dietary diversity were about 5 times more likely to be house hold food insecure compared to those with low dietary diversity AOR=4.990(2.488,10.05), AOR=4.696(1.54,14.36), respectively.

Conclusions:Food Security status among People living with HIV/AIDSon ART in Hawassa town was low. Dietary diversity, household size, and disclosing HIV status were found to be significant predictors of food security. Key words: Food security, food insecurity ,Adult living with HIV/AIDS.

\section{Background}

Globally 78 million people have been infected with HIV and 34 million people have died of HIV related cause due to AIDS epidemic. In 2015, 36.7 million people were PLWHA; and among those 2.1 million became newly infected and 1.8 million, down from 3.1 AIDS-related deaths. Sub-Saharan Africa remains the region most heavily affected by HIV worldwide, accounts more than $2 / 3$ of all people living with HIV and for nearly three quarters of AIDS-related deaths in 2015 (1\&2) .

Ethiopia has one of the largest populations of HIV infected people in the sub-Saharan region of Africa. According to statistics single point estimate and federal HIV/AIDS Prevention and Control Office (FHAPCO), the HIV/AIDS epidemic in Ethiopia continues to pose a threat to the lives of its people. It is estimated that 759,338 people live with the virus in $2015(2 \& 3)$.

Study done in West Shewa Zone, Central Ethiopia indicated that the prevalence of household food insecurity with PLWHA was $35.2 \%$ (4).

In SNNPR, it is estimated that 169,700 people live with the virus. Whoever enrolled in the program and of which a total of 20,340 PLWHA were started ART since the initiation of the program. The regional adult Population (15-49) age prevalence of PLWHA in 2010 was estimated to be 1.7\% (3).

Food insecurity is no longer seen simply as a failure of agriculture to produce sufficient food at the national level, but instead as a failure of livelihoods to guarantee access to sufficient food at the household level and at individual level .Food security and adequate nutrition are fundamental to HIV treatment. There is emerging evidence that patients who begin ART without adequate nutrition have lower survival rates. Given the 
importance of adherence in delaying viral resistance to first line drugs, nutritional support becomes even more important in the longer run for sustaining ART (5\&6).

Many families throughout the developing world spend more than $50 \%$ of their household income on food, and food production and wage earning are adversely affected when an adult has AIDS. Food insecurity and poverty may lead to high-risk sexual behaviors and migration, increasing the risk of acquiring HIV. At the same time, HIV weakens a household's ability to provide for basic needs (7\&8).

In Hawassa city administration, little is known about the level of household food security and associated factors among adult people living with HIV / AIDS attending ART Clinic. Therefore the objective of this study was to assess the level of food security and associated factors among adult people living with HIV/AIDS in case of Hawassa city administration hospitals 2017.

\section{Methods}

\section{Study area and Period}

The study was carried out in Hawassa town which is the administrative city of SNNPR. This town is located $275 \mathrm{~km}$ south to Addis Ababa. There are two governmental hospitals in the town; Hawassa compressive referral specialized Hospital and Adarea Hospital. There are 8 governmental health centers and one nongovernmental health center and 15 health Posts which Deliver health services people from the SNNPRS and Oromia regions. Hawassa town have 328,283 total populations from this 168,886 Male and 159,397 were Females. Since 1998 E.C in Hawassa comprehensive referral specialized hospital and 1999 E.C in Adarea hospital the initiation of ART service were started in both Hospitals. The study was conducted from OctDec/2017.

Study design

Institution based cross-sectional study design was conducted from Oct-Dec/2017

\section{Source population}

The source populations were all PLWHA on Antiretroviral Treatment registered andhave a follow up for their treatment in Hawassa city administration at the time of the study.

Study population

The study population were all PLWHA on HAART whose age is $>18$ years regardless of their treatment regimen, duration of follow up category during the study period, and available during data collection period.

\section{Inclusion criteria}

Systematically selected Adult PLWHA whose age $\geq 18$ years regardless of their treatment

\section{Exclusion criteria}


Those adults who were ill and unable to respond to the questions.

Sample size and sampling technique

\section{Sample size}

The required sample size were estimated by single proportion estimation method .The study done in DireDawa town showed that $72 \%$ of the respondent was food insecure .By using the $72 \%$ proportion , $5 \%$ Precision and $95 \%$ confidence level was taken(9).

Sample size ' $n$ ' was determined by using single population proportion formula with the

Following assumptions:

\95\% level of confidence $(Z= \pm 1.96)$

$\nabla$ Margin of error $(\mathrm{d}=4 \%)$

$\nabla$ Considering Non-Response rate $=5 \%$

$\nabla$ Prevalence $=72 \%$

$N=(1.96) 2 * 0.72 * 0.28=484$

$(0.04) 2$

Adding 10\% for non-response was given an overall sample size of 532 .

Sampling procedure

There are a total of four health facilities which provide ART services in Hawassa city administration and all of them provide the services free of cost. Hawassa referral comprehensive specialized hospital and Adare hospitals were randomly selected using lottery method and the samples were proportionally allocated to each of the selected health facilities. The study participants were selected randomly using a computer generated simple random based on patient ART unique identification number.

Random selection of participants was done prior to patients presenting to clinic.

Data quality assurance

At the beginning, questionnaire was pretested on, $5 \%$ of the samples at Yirgalem Hospital and the question modifications was incorporated to the questionnaire and not included in the actual study. The interview was conducted in private room to create an atmosphere of empathy and confidence within a secure environment. Three days training was given for all supervisors (2 public health officers) and data collectors ( 6 nurses) before the process of data collection. The overall activities were controlled by the principal investigator of the study and proper designing of the data collection materials and continues supervision during data collection 
was perform. All complete questionnaires were examined for completeness and consistency during data management, storage and analysis.

\section{Data collection instrument}

A pre-tested structured questionnaire was prepared in English language first and then translated in to local language, and back translated to English in order to ensure consistency. Questionaries' were adopted from the Global United States Household food security scale and from different literatures $(10,11 \& 12)$ used to assess the household food security level of PLWHA on ART. It consisted of 18 questions in the core module to assess food security and questions to assess dietary diversity and meal frequency situation of households. The optional first question was used as part of the first-stage screener in the core module proper, and/or for its additional information content. The instrument also contains questions related to dietary diversity and meal frequency situation of the households, socio-demographic (age, sex, education, occupation, religion, job, Household size and marital status), socio-economic variables (family income) and behavioral factors (alcohol intake, smoking habit, substance addiction).

\section{Data analysis}

The collected data were entered and coded in to Epi-info 3.5.4 version statically package and imported in to SPSS version 20 software. Frequency distribution and percentages were computed and presented by tables to describe socio-demographic and other characteristics of respondents. Both bivariate and multivariate logistic regression analysis was done to determine the association of the variables. Variables significant analysis $(p<0.25)$ entered in to multivariate logistic regression. Odds ratio with $95 \% \mathrm{Cl}$ and statically significant were declared $p<0.05$.

\section{Measurements}

\section{Food security and dietary diversity scales}

To measure food security status of the households, number of affirmative answers were provided by study participants for the 18 questions which were applicable to household in the presence of children; however house hold without children were used only maximum 10 possible affirmative answers. Households responses had scored from a total of 18 questions (each score as 1 for affirmative response and 0 for negative response). The total scored range (1-18) was categorized in to four food security statuses as indicate below.

\begin{tabular}{lll}
$0-2$ & Food & secured \\
\hline $3-7$ & Food & insecure without hunger \\
\hline $8-12$ & Food & insecure with moderate hunger \\
\hline $13-18$ & Food & insecure with sever hunger
\end{tabular}

Households response score for those who do not have children from a total of 10 questions (coded by 1 for affirmative response and 0 for negative response). Total score range (1-10) was categorize in to four food security statues as indicate below 
0-2 Food secured

3-5 Food insecure without hunger

6-8 Food insecure with moderate hunger

9-10 Food insecure with sever hunger

Two of the questions which indicate the number of eating occasion and twelve of the questions were used to assess dietary diversity. Individuals who scored more than the mean value were considered as having a good diversity scores (13). The way the dietary diversity was calculated should be made clear as follows: The dietary diversity was assessed using a the questions specifically covered food consumption during the past 24 hr. period containing Cereals, Miscellaneous, Oils/Fats, Honey/Sugar, Legumes, Fruits ,Vegetables, Meat, Milk/Milk products, Eggs, Fish that. Participants were asked to report the frequency of consumption of each food using the past 24 hours. Participants received 1 point if they consumed at least once during the last 24 hours of the foods within each subgroup and 0 points if they never consumed the food. The food items were grouped into six according to the food guide pyramid (US Department of Agriculture, 1992). A Dietary Diversity Score (DDS) was calculated as the sum of the food groups consumed over 24 hours. The dietary diversity score ranged from one to twelve. The mean $( \pm S D)$ dietary diversity score in the study group was $4.47( \pm 1.1)$.

\section{Operational definitions}

Household's food security status: a household was classified in to one of the food security status level categories on the basis of its score on the food security scale, while the households' scale score is determined by it's over all pattern of response to the set of indicator questions. Households responses were scored from a total of 18 questions (each scored as " 1 " for affirmative response and "0" for negative response) and total scores (range 0-18) and its categorization was mentioned in the data measurement section above.

Meal frequency: is the number of eating occasions by an individual experience within a day. In this study respondents were ask the number of meal occasions they have in the preceding $24 \mathrm{hrs}$. This does not include eating occasions by the house hold members outside home.

Dietary diversity: is the number of different foods and food groups consumed by an individual over a 24-hour period. For the purpose of this study dietary diversity score were calculate based on the number of the four major food groups i.e. Cereals legumes and tubers, Vegetables and fruits, Animal source foods and Oil/ fat and sugar consumed over the 24 hours period and dichotomized as diversified and non-diversified based on the median number of food groups consumed.

Nutritional care: delivering of food and health service in the institution

\section{Ethical approval and Consent to participate}

This study was conducted in accordance with the Declaration of Helsinki. Ethical clearance was obtained from institutional review board of institute of public health and Permission from SNNPR Health Bureau of research and technology sub core process, Hawassa referral and Adarea District Hospitals. In addition, letter 
of support from NOSAP+ (Network of south Association of Positives) that works on the rights and wellbeing of member of PLWHA were taken before commencing the data collection process. During data collection process the data collectors were informed each study participant about the purpose and anticipate benefits of the research project and the study participants were also inform on their full right to refuse, withdraw or completely reject part or all of their part in the study and they were assured that their treatment and other benefits they gain from the hospital and/or other organizations was not be influenced by their participation in the study. Finally, they were asked for their informed written consent to participate or not to participate in the study and for their willingness on use of their files and records for the study.

\section{Results}

\section{Socio-demographic characteristic of respondent}

A total of 532 adult people living with HIV/AIDS were involved in the study giving a response rate of $100 \%$. The mean ages of the study participant were 35.9 ranging between 18 and 65 year. $21.63 \%$ (115) of respondents were unable to read and write followed by 114 (21.4\%) of the respondents were attended elementary school and $144(27.1 \%)$ of the respondents were educated up to high school level. 201 (37.8\%) of the respondents were employed while $26.3 \%$ (140) were jobless and financially dependent See table 1.

\section{Clinical-condition}

Majority of the study participants had been on ART for more than one year with Mean duration of 35 months. In terms of overall health condition 232(43.6\%) participants had been excellent and 162(30.5\%) very good report at the time of data collection. The mean CD4+ cell count of the respondents were 131 cells $/ \mu \mathrm{L}$ at the time of initiation of therapy. During data collection, however, clients had a mean CD4+ cell count of 385 cells/ $\mu \mathrm{L}$. More than $83 \%$ of the patients who had their CD4+ cell counts recorded at the start of treatment and had CD4 cell count less than 180 cells $/ \mu \mathrm{L}$ (median of $125 \mathrm{cells} / \mu \mathrm{L}$ ) by the time of initiation of therapy; while inspection of the latest visit record of PLWHA revealed that some about $77 \%$ of the respondents had their latest CD4 counts > 235 cells/ $\mu \mathrm{L}$ with maximum and median values of 1163 and 345 respectively.

\section{Dietary diversity}

Based on the assessment, cereal food group and beverages such as tea and coffee were among the most commonly consumed food groups by $98.1 \%$ and $95.5 \%$ of the respondents respectively. While eggs and fishes were among the least consumed food groups.74.4\% of the respondents answered that their usual meal frequency was three times a day during the preceding 24 hours.

Similarly, $70.3 \%$ of the respondents had number of meal pattern three times a day during the preceding $24 \mathrm{hrs}$. of the survey, while 263 (49.4\%) of the study subjects reported that their food supply and number of meals in a day was not enough see table 2.

\section{Food security}

Majority of the PLWHA Households on ART in the study was food in secured. Most of them (any member of the households they are living in) eat less than the mean meal frequency (67.7\%) and less than the mean 
dietary diversity $(62.7 \%)$ in the preceding 24 hours of the survey. 396(74.4\%) of the respondents were eat 3 times per day, 82(16.2\%) were 2 times per day. overall food security status of households PLWHA on ART about 172 (32.3\%) were food secured and 360 (67.6\%) were food insecure. Food insecurity were classified in to three part i.e. food insecure without hunger, food insecure with hunger moderate and food insecure with sever hunger. Accordingly 162 (30.5\%), 123 (23.1\%) and 37(13.7\%) were food insecure without hunger; food insecure with hunger and food insecure with sever hunger respectively see fig 2.

Factors Affecting House Hold food Security of PLWHA

The study showed that low household size had better food secured than medium \& high household sizes. Low household size was 3times more likely secured than high household size or the low household size $68 \%$ more likely secured than high household size. Those who were with high house hold size were about 4 times more likely to food insecure compared to those with low house hold size (AOR=3.769 95\% Cl $(1.313,10.8)$. Similarly, those who were with high and medium dietary diversity were about 5 times more likely to be house hold food insecure compared to those with low dietary diversity AOR $=4.990(2.488,10.05, A O R=$ 4.696(1.54,14.36), respectively.

This study result indicated that low or absence of nutritional care was 4 times less likely food secured than presence of nutritional care with AOR $=3.902(1.238,12.301)$. Those who didn't disclose their status were 2 times more likely to be food insecure with $A O R=2.359(1.312,4.241)$ see table3.

\section{Discussion}

According to the food security assessment module score, which is validate for use in developing countries (13). 32.7\% to household with PLWHA on ART in Hawassa town were food secured. Sixty-seven percent of PLWHA on ART were food insecure ranging from mild food insecurity without hunger (30.5\%) to sever food insecurity with hunger $(13.7 \%)$. while the majority had insecure without hunger. The meal frequency and dietary diversity scores supported the findings of the core module which yielding significant proportion of PLWHA eating less than the mean frequency (67.7\%) and dietary diversity (62.7). This might be explained by the fact that the disease reduces access to food for many affected households due to decreased labor availability and income, erosion of saving and productive assets, and increased health care and other related expenses (14). This level of food insecurity closely compared to the findings of similar study in Zambia where, the results showed that most of those on ART were food in secured. Only $6 \%$ were food secure, $24 \%$ insecure without hunger, $34 \%$ somewhat food insecure and $36 \%$ had severe food insecure with hunger (15). However, the food insecurity figure in this study is markedly higher than the estimated level of food insecurity in general population at national level of our country (Ethiopia), 41\% secure and 59\% food insecure in 2010 (16) .

This disparity of food insecurity among the general population and PLWHA may be explained by the popular notions that HIV/AIDS affects food security and livelihoods of individual, households and communities and the abilities of individuals\& households to feed and care for themselves, while eroding the capacity of communities and institutions to provide basic service and support for people in need House hold size associated with food security. 
The study indicated that small household size was 3.7 times more likely to be food secured compared with large house hold size (AOR=3.769, 95\% Cl $(1.313,10.823)$.

Household size revealed a negative relationship with food security and statistically significant $(p<0.05)$. Food security decreases by a factor of $3.8 \%$ as household size increases by one. The possible reason is that with existing high rate of unemployment and less employment opportunity coupled with low wage rate payment, an additional household member shares the limited resources that lead the household to become food insecure (17).

In 2007 Qualitative Cross sectional study conducted in Southern Ethiopia of wolaita and sidama zone showed that the risk of food insecurity increases with household size: i.e. Households with4- 6 members were $79 \%$ less likely to become food secured compared to household size with 0-3 and households with 7+members were 69 $\%$ less likely to become food secured. Compared with this study the food security status was lower than that of wolaita and sidama zone study. Household with 4-6 members were $98 \%$ less likely to be food secured compared with household size with reference category .similarly households with $7+$ members were $96 \%$ less likely to become food secured. This indicates that large family size negatively affects household food security (18). Household dietary diversity also affected the functional improvement of PLWHA on ART.

Increases in dietary diversity are associated with increase in consumption, caloric availability and calories from staple and non-staples (32, 33, and 34) PLWHA who disclose their status had a positive association with food security. This study revealed that PLWHA on ART who disclosed their status was 2.4 times more likely to be food secured than those who was not disclosed (AOR, 2.359, 95\% Cl (1.312, 4.241). Not to disclosing HIV status usually was due to fear of discrimination or stigma. Stigma was one of the barriers to adherence to ART. One review paper reported being embarrassed to take medications in front of family, friends, or coworkers was one of the reason not to be adhere in USA (19).

People who do not disclose their HIV status due to fear of stigma and discrimination, will not follow their treatment as protocol so that leads to lack of maximum adherence level to have adequate viral suppression. This again resulted in impairment of immune function, development of opportunistic infections, poor functional status and, decreased productivity. People who fear to disclose their HIV status will also have lack of social support like food aid and other similar events; hence they are prone to be food insecure. (17) The association of food security with nutritional care variable in this study showed that household PLWHA on ART those have not nutritional care were $96 \%$ less likely food secured than that of the house hold PLWHA on ART who have nutritional care. $(\mathrm{AOR}=3.902,95 \% \mathrm{Cl}(1.238,12.301)$.

\section{Conclusions}

The study find out that food security is a prevailing problem among PLWHA on ART touching massive proportion of PLWHA in Hawassa town which affecting virtually all dimensions of their lives including their clinical health problem. Although it's long effect was realized by the significant association of household size, dietary diversity, nutritional care and disclosure. But, in this study it is suggested that to maintain food security among PLWHA on ART should give priority to intervene and emphasizes the need to address food as an essential part of ART treatment and immunization. 


\section{Abbreviations}

AIDS Acquire immune deficiency syndrome

ART Anti-retroviral therapy

DDS Dietary diversity score

FHAPCO federal HIV/AIDS prevention and control office

HIV Human immune virus

PLWHA People living with HIV/AIDS

SNNPR South nation, nationalities and people region

SPSS statically package for social science

SPSS statically package for social science

\section{Declarations}

Consent for publication

Not applicable.

Availability of data and materials

The datasets analyzed during the current study are available from the corresponding author on reasonable request.

\section{Competing interest}

The authors declare that they have no competing interest

\section{Funding}

The source of fund is south region health bureau. This funding organization has no role in designing, collection and analysis of data.

\section{Author's contribution}

TS: Actively involved from proposal development to final data analysis.

RF: Actively participated in data analysis.

All authors have read and approved the manuscript 
We are very grateful to Gondar University for approval of ethical clearance. We also thank south region health bureau for provision of information and support to do this work. Then we also thank participant, data collectors and supervisor for their hard work and patience

\section{References}

1. Joint United Nations Programme of HIV/AIDS (UNAIDS) Aids epidemic update. Geneva, UNAIDS and the World Health Organization, journal of public health. 2015.

2. Federal Democratic Republic of Ethiopia and Federal HIV/AIDS prevention and control office. Report on progress towards implementation of the UN Declaration of commitment on HIV/AIDS 2010. March 2010, Available online at: www.unaids.org or http://www.etharc.org/arvinfo/index.htm),

3. Central Statistical Agency [Ethiopia] and ORC Macro: Ethiopia Demographic and Health Survey report 2011. Addis Ababa, Ethiopia and Calverton, Maryland, USA: Central Statistical Agency and ORC Macro. . 2015.

4. Delelgn Y.,Kokbe T. et.al. Food Insecurity, Nutritional Status, and Factors Associated with Malnutrition among People Living with HIV/AIDS Attending Antiretroviral Therapy at Public Health Facilities in West Shewa Zone, Central Ethiopia ,BioMed Research InternationalVolume 2018, Article ID 1913534, 9 pages

5. Piwoz, E., and E. Preble. HIV/AIDS and nutrition: A review of the literature and recommendations for nutritional care and support in sub-Saharan Africa. SARA Project. Washington, D.C.U.S. Agency for International Development 2000.

6. United Nations Programme of HIV/AIDS (UNAIDS). HIV Food security in Ethiopia. Journal of public health. 2006.

7. S.Mukherjee. Antiretroviral therapy in resource poor settings decreasing barriers to access and promoting adherence journal of acquire Immune deficiency syndrome. 2006; 43(s):123-6.

8. World Bank. HIV/AIDS, nutrition and food security: what we can do? A synthesis of international guidance 2007

9. Abiy S. Impact of Household food security and nutrition on Adherence to ART and Response to treatment among PLWHA on ART in Dilchora Hospital Master thesis submitted to Addis Ababa University 2007.

10. World food programme (WFP). Ethiopia food security update. FANTA 2009 http://www.dec.org/ and at http://www.usaid.gov

11. Swindale A. Household Dietary Diversity Score (HDDS) for measurement of household Food access; Indicator guide journal of nutrition 136; s1449-1452. 2005; 136

12. Abiy S. Impact of Household food security and nutrition on Adherence to ART and Response to treatment among PLWHA on ART in Dilchora Hospital Master thesis submitted to Addis Ababa University 2007.

13. Seifu A: Impact of food and nutrition security on adherence to Anti-Retroviral Therapy (ART) and treatment outcomes among Adult PLWHA in Dire Dawa provisional administration June 2007. Accessed May 2010, at http://hdl. handle.net/123456789/861 
14. Morteza Rafiei.Mark Nord .Atefeh sadeghizadeh .Mohammed .H.Entezari.Assessing the internal validity of a household survey based food security measure adapted for use in Iran. Nutrition journal 2009, 8:28

15. Etheldreda N, Brian M, Makanga $O$, and seggane M. Psychological distress and adherence to highly active anti-retroviral therapy (HAART) in Uganda : A pilot study Africa health Science 2009; 9(S1) : 2-7

16. Overseas Development Institute. HIV, food and drugs Livelihoods, nutrition and Ant- retroviral therapy (ART) in Kenya and Zambia. Briefing paper, December 2008 (availability online at: www.odi.uk) , (accessed on $20^{\text {th }}$ march 2010)

17. Laura c Anderson AT, Fasil Tessema. Food insecurity, childhood illness and maternal emotional distress in Ethiopia 2010(15(4)):648-55.

18. Zuurmond M. Adherence to ARVs challenges and successes, (CAFOD) partners and members of the catholic HIV\& AIDS network. 2008

19. Asefach Hailu NR. Correlates of Household Food Security in Densely Populated Areas of Southern Ethiopia: Does the Household Structure Matter? @ Kamla-Raj. 2007; 1(2):85-91.

20. Health Aus Dop. Adherence to HIV Antiretroviral therapy. Clinical manual of ARV therapy. 2006.

\section{Tables}

Table1. Socio demographic characteristics of Households food Security among PLWHA on ART in Hawassa Town Hospitals, 2017.

\section{HOUSE HOLD FOOD SECURITY STATUS}


Variables

Security Insecure

\begin{tabular}{|c|c|c|c|}
\hline & & Frequency & Frequency \\
\hline \multirow[t]{4}{*}{ Sex } & Male & $67(35.8 \%$ & $120(64.2 \%)$ \\
\hline & Female & 105(30.4\% & $240(69.6 \%)$ \\
\hline & $<20$ & $21(58.3)$ & $15(41.7)$ \\
\hline & $20-24$ & $31(33.3 \%)$ & $62(66.7)$ \\
\hline \multirow[t]{5}{*}{ Age } & $25-29$ & $27(24.1 \%)$ & $85(75.9 \%)$ \\
\hline & $30-39$ & $40(27.2 \%)$ & $107(72.8 \%)$ \\
\hline & $40-49$ & $26(41.8 \%)$ & $59(65.6 \%)$ \\
\hline & $50-59$ & $21(34.4 \%)$ & $29(58.2 \%)$ \\
\hline & $60(+)$ & $6(66.7 \%$. & $3(33.3 \%)$ \\
\hline \multirow[t]{5}{*}{ Marital status } & Married & 61(128.1\%) & $156(71.9 \%)$ \\
\hline & Unmarried & $39(40.2 \%)$ & $58(59.7 \%)$ \\
\hline & Divorce & $34(31.5 \%)$ & $74(68.5 \%)$ \\
\hline & Widowed & $38(37.6 \%)$ & $63(62.3 \%)$ \\
\hline & /widower & & \\
\hline \multirow[t]{3}{*}{ Household Size } & $\operatorname{Low}(0-3)$ & $122(36.6 \%)$ & $211(63.4 \%)$ \\
\hline & Medium(4-6) & $37(21.6 \%)$ & $134(78.4 \%)$ \\
\hline & Large7(+) & 13 (46.4\%) & $15(53.6 \%)$ \\
\hline
\end{tabular}

Educational

\begin{tabular}{llll}
\hline status & No read/write & $28(24.3 \%)$ & $87(75.7 \%)$ \\
\hline & Read \& write & $35(49.3 \%)$ & $36(50.7 \%)$ \\
\hline Elementary & $18(15.8 \%)$ & $96(84.2 \%)$ \\
\hline High school & $50(34.7 \%)$ & $94(65.3 \%)$ \\
& Diploma + & $41(46.6 \%)$ & $47(53.4 \%)$ \\
Occupation & None & & \\
\hline
\end{tabular}




\begin{tabular}{lll} 
Employed & $70(34.8 \%)$ & $131(65.2 \%$ \\
\hline Farmer & $10(62.5 \%)$ & $6(37.5 \%$ \\
\hline Trader & $44(44.9 \%)$ & $54(54.1 \%)$ \\
\hline Self employed & $23(29.9 \%)$ & $54(70.1 \%)$
\end{tabular}

Table2. Distribution of food groups consumed 24 hrs. preceding the survey of Household Food Security among PLWHA on ART in Hawassa Town Hospitals, 2017.
Dietary diversity Frequency
Percentage

\begin{tabular}{lcccc} 
& S & I & S & I \\
\hline Cereals & 526 & 6 & 98.9 & 1.1 \\
\hline Roots and tubers & 292 & 240 & 54.9 & 45.1 \\
\hline Vegetables & 201 & 331 & 37.8 & 62.2 \\
\hline Fruits & 142 & 390 & 26.7 & 73.3 \\
\hline Meat & 165 & 367 & 31.0 & 69 \\
\hline Eggs & 67 & 465 & 12.6 & 87.4 \\
\hline Fish/sea foods & 43 & 489 & 8.1 & 91.9 \\
\hline Pulses/legumes & 387 & 145 & 72.7 & 27.3 \\
\hline Milk/milk product & 170 & 362 & 32.0 & 68 \\
\hline Oil/fat & 352 & 180 & 66.2 & 33.8 \\
\hline Sugar/honey & 154 & 378 & 28.9 & 71.1 \\
\hline tea and coffee & 445 & 87 & 83.6 & 16.4
\end{tabular}

Table3. Binary logistic regression analysis of determinants of Household Food Security among PLWHA on ART in Hawassa Town Hospitals, 2017. 
Predictor

\begin{tabular}{|c|c|c|c|c|c|}
\hline & & Secure & Insecure & & \\
\hline \multirow[t]{4}{*}{$\begin{array}{l}\text { House hold } \\
\text { size }\end{array}$} & $\begin{array}{l}\operatorname{Low}(0- \\
3)\end{array}$ & $122(36 . \%$ & $211(63.4 \%$ & 1 & 1 \\
\hline & $\begin{array}{l}\operatorname{Med}(4- \\
6)\end{array}$ & $37(21.6 \%)$ & $134(78.4 \%$ & $1.499(.690,3.255)$ & $2.283(.829,6.283) \star$ \\
\hline & High7(+) & $13(46.4 \%)$ & $15(53.6 \%)$ & $3.139(1.373,7.18)$ & $3.769(1.313,10.8)^{*}$ \\
\hline & & $4(7 \%)$ & $53(93 \%)$ & 1 & 1 \\
\hline Dietary & $L o w \geq 3$ & & & & \\
\hline \multirow[t]{3}{*}{ Diversity } & Med 4 & 13(12. \% & $91(87.5 \%)$ & $9.508(3.371,26.82)$ & $4.696(1.54,14.36)^{\star \star}$ \\
\hline & $\mathrm{High} \geq 5$ & $155(41 \%$ & $216(58.2)$ & $5.023(2.711,9,307)$ & $4.990(2.488,10.05)^{\star}$ \\
\hline & & $2(2 \%)$ & $98(98 \%)$ & 1 & 1 \\
\hline \multirow{2}{*}{$\begin{array}{l}\text { Meal } \\
\text { frequency }\end{array}$} & Low & & & & \\
\hline & High & $170(39 \%$ & $262(60.4 \%$ & $31,794(7.737,130.64$ & $28.450(6.524,34.064)^{\star \star}$ \\
\hline \multirow{2}{*}{$\begin{array}{l}\text { Nutritional } \\
\text { care }\end{array}$} & Yes & $4(5.7 \%)$ & $66(94.3 \%)$ & 1 & 1 \\
\hline & No & $168(36 \%$ & $294(63.6 \%$ & $9.429(3.37726328)$ & $3.902(1.238,12.301)^{\star}$ \\
\hline \multirow[t]{2}{*}{ Disclosure } & Yes & $126(29 \%)$ & $308(71 \%)$ & 1 & 1 \\
\hline & No & $46(46.9 \%$ & $52(53.1 \%)$ & $2.115(1.349,3.316)$ & $2.359(1.312,4.241)^{\star}$ \\
\hline \multicolumn{6}{|l|}{ Educational } \\
\hline \multirow[t]{5}{*}{ Status } & $\begin{array}{l}\text { No } \\
\text { read/writ }\end{array}$ & $28(24 . \%$ & $\begin{array}{l}87 \\
(75.7 \%)\end{array}$ & & \\
\hline & Read write & $35(49.3 \%$ & $36(50.7 \%)$ & $2.710(1.492,4.926)$ & $1.070(.527,2.175)$ \\
\hline & Elem & $18(15.8 \%$ & $96(84.2 \%)$ & $.897(.480,1.678)$ & $.591(.283,1.234)$ \\
\hline & High school & $50(34 . \%$ & $94(65.3 \%)$ & $4.652(2.417,8.96$ & $2.131(1.011,4.494)$ \\
\hline & Diploma (+) & $41(46.6 \%)$ & $47(53.4 \%)$ & $1.640(.954,2.818)$ & $1.040(.567,1.906)$ \\
\hline
\end{tabular}




\section{Drug Discontinue Yes $\quad 21(26.2 \%) \quad 59(73.2 \%) \quad 1.409(.825,2.704)$ \\ No $\quad 151(33.4 \%) \quad 301(66.6 \%)$}

\section{Figures}

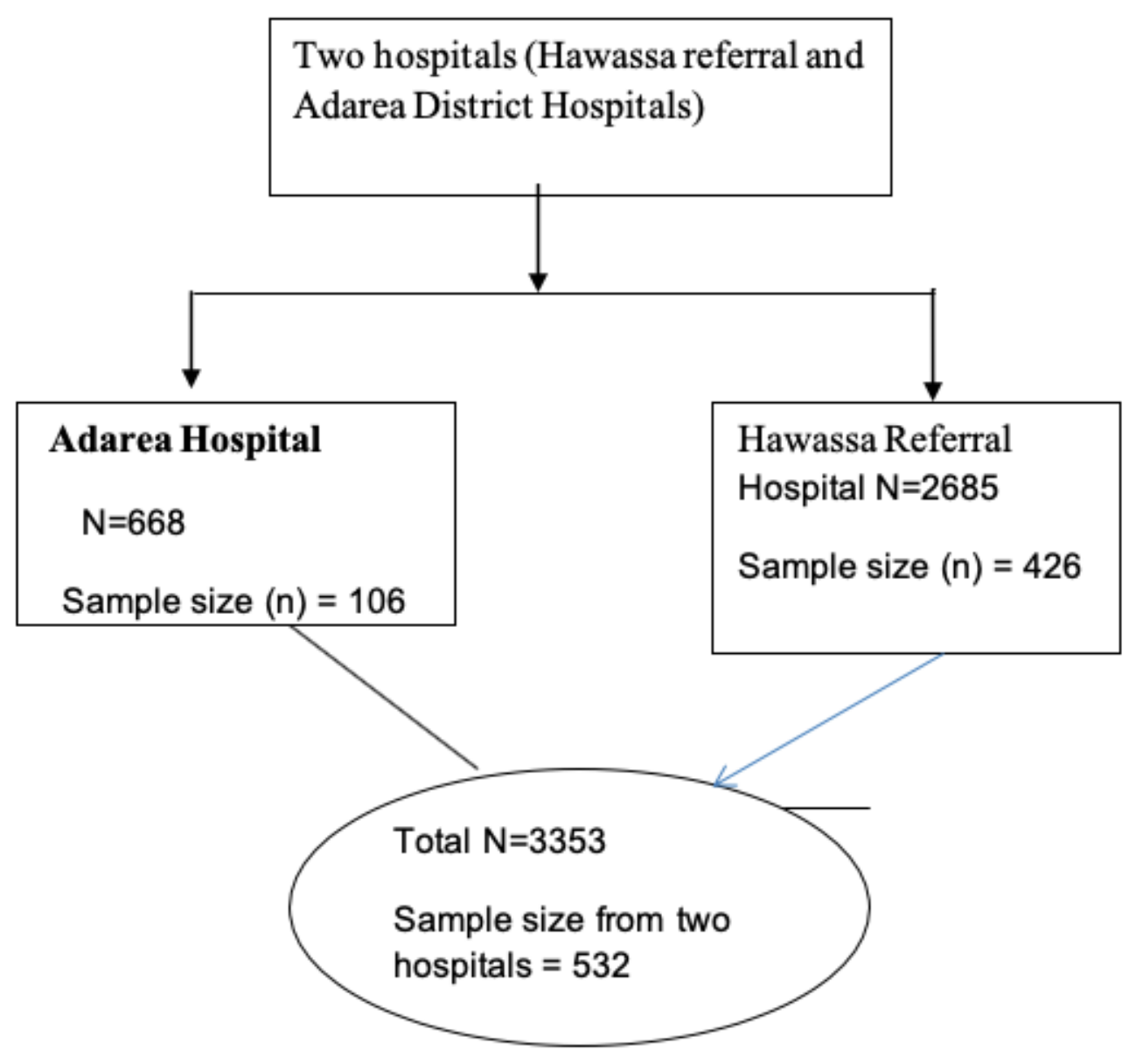

Figure 1

Conceptual Model of Household Food Security among PLWHA on ART in Hawassa Town Hospitals, 2017. 


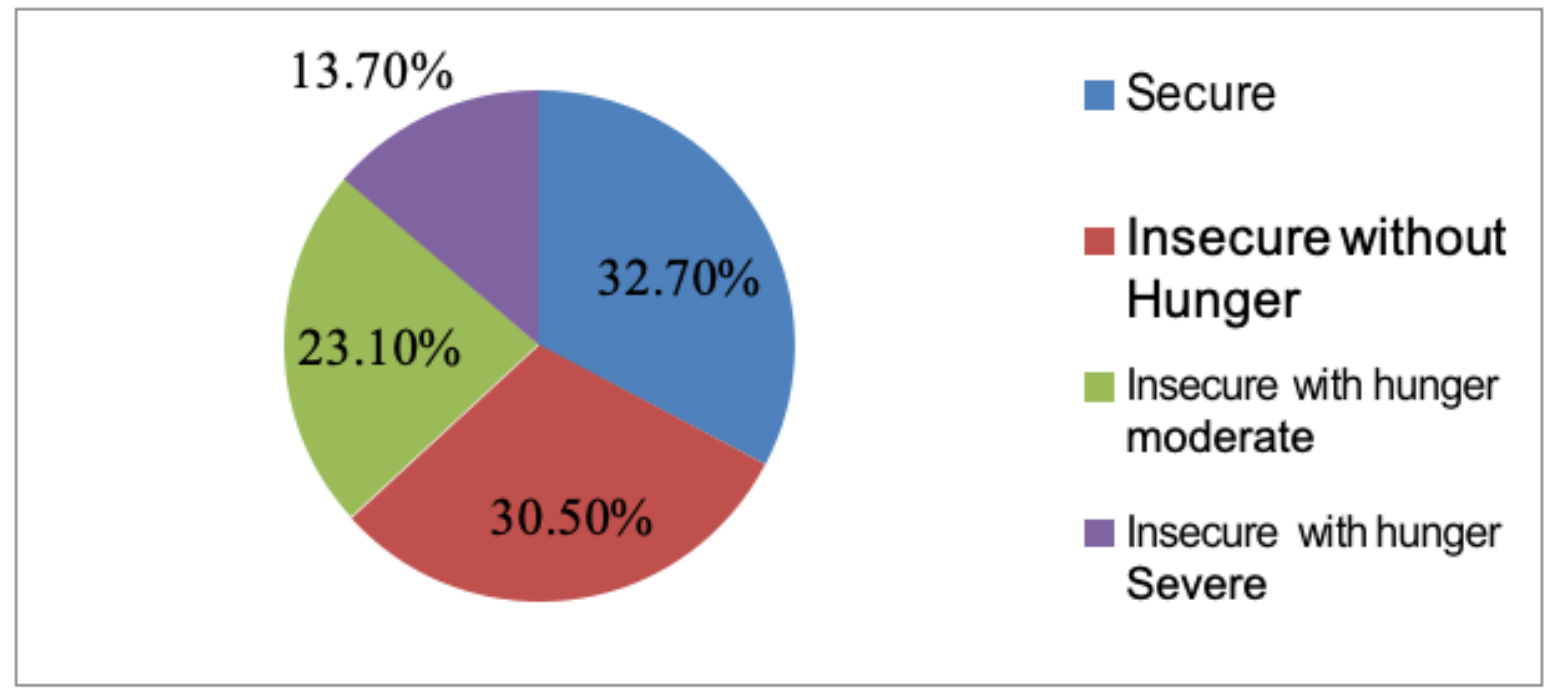

\section{Figure 2}

Over all Food Security Status of Household Food Security among PLWHA on ART in Hawassa Town Hospitals, 2017. 